\title{
Deposition Thickness Sensor for Ion Sputtering Apparatus
}

\author{
Member Hironori Kumazaki (Gifu National College of Technology) \\ Member Seiki Inaba (Gifu National College of Technology) \\ Member Kazuhiro Hane (Tohoku University)
}

\section{Summary}

\begin{abstract}
A quartz core microcantilever fabricated from an optical fiber tip can be utilized for monitoring of deposition thickness. Dynamic monitoring of deposition thickness was performed without influence of electrical noise in an ion sputtering apparatus. Resonance frequencies were measured as a function of deposition time of $\mathrm{Au}$ and Ag. Resonance frequency decreased from $11.52 \mathrm{kHz}$ to $10.89 \mathrm{kHz}$ during a deposition time of 60 minutes which corresponded to a thickness of $360 \mathrm{~nm}$ in case of $\mathrm{Au}$
\end{abstract}

Key words: optical sensor, quartz core microcantilever, ion sputtering apparatus, in situ film thickness measurement,

\section{Introduction}

Monitoring the thickness of thin films during vacuum deposition is generally accomplished by the use of oscillating quartz-crystal resonators. Such resonators are widely used for control of evaporation rate and for in situ film thickness measurement in coating processes in the optics and semiconductor industries. The resonator is electrically excited while the crystal is coated by the same process as the substrate, and the frequency change caused by the mass load on the crystal is used to calculate the thickness of the film. The measurements are simple and can be continued during the film deposition process. However, in sputtering, since considerable electrical noise is caused by collision of plasma with the electrodes, the resonance frequency cannot be measured unless the sensor head is electrically shielded from the discharge region [1]

We have previously fabricated a microcantilever from a quartz core by etching the clad layer of a fiber tip [2] in order to develop a photomechanical sensor for measurements of pressure and viscosity. It was photothermally vibrated by light transmitted through the optical fiber. Resonance characteristics of the vibration are steady and unaffected by electrical noise.

In this work, the resonance frequencies of this cantilever were measured as a function of deposition time of Au using an ion sputtering apparatus for in situ film thickness measurement (dynamic monitoring).

\section{Experiment}

A schematic view of the fabricated cantilever is shown in Fig.1. The clad layer on the tip of an optical fiber (multimode $50 / 125 \mu \mathrm{m}$ graded index type) was removed by chemical etching. The fiber tip was dipped in a solution composed of $50 \%$ hydrofluoric acid (HF), 40\% ammonium fluoride $\left(\mathrm{NH}_{4} \mathrm{~F}\right)$ and water $\left(\mathrm{H}_{2} \mathrm{O}\right)$ for etching [3]. The diameter of the cantilever was adjusted by controlling the temperature and time of etching. $\mathrm{Cr}$ and $\mathrm{Au}$ were deposited on one side of the core of the fiber tip to absorb the laser light used to induce the vibration. Finally, the quartz core was fixed in a stainless steel tube with epoxy resin at an appropriate distance from the fiber tip.

Figure 2 is a block diagram of the experimental system for deposition thickness monitoring. The quartz core

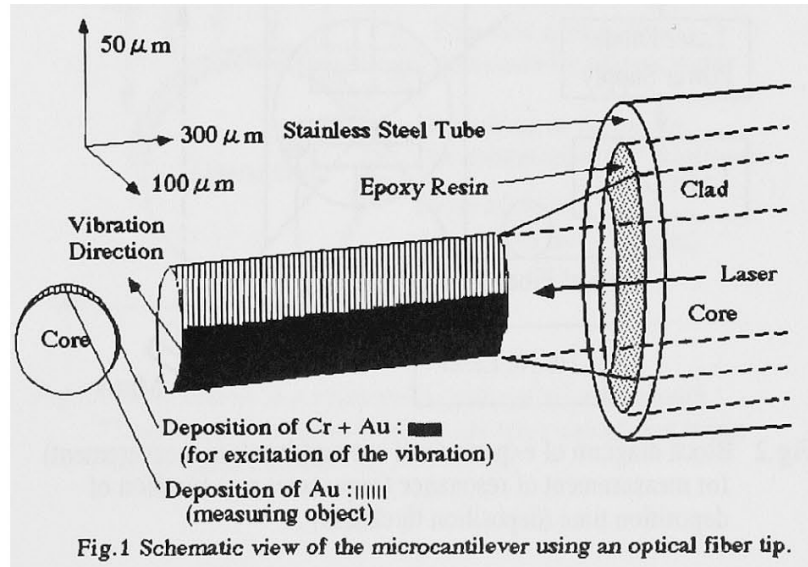


cantilever was set on the center of the lower electrode in an ion sputtering apparatus. The laser diode (Neo Arc LF8340, wavelength $830 \mathrm{~nm}$, maximum laser power $40 \mathrm{~mW}$ ) was connected to the optical fiber with a FC connector at the window of the chamber. The light from the laser diode was modulated at a frequency of $\sim 12 \mathrm{kHz}$ by a voltage-frequency converter. The quartz core cantilever was efficiently irradiated through the optical fiber. The light was absorbed at the $\mathrm{Cr} / \mathrm{Au}$-deposited side of the cantilever, but not at the other side. Thus, the cantilever was bent photothermally with the same period as the modulation frequency. Since the $\mathrm{Cr} / \mathrm{Au}$-deposited side of the cantilever faced the window of the chamber, the cantilever was vibrated horizontally. The vibration was monitored using the light of a $\mathrm{He}-\mathrm{Ne}$ laser reflected from the Au layer through a slit. The light signal was transformed to an electrical signal according to the displacement of the reflected light at the entrance of a photomultiplier and was detected using a lock-in amplifier. The resonance frequency was measured by detecting the peak point of the resonance curve on an X-Y recorder at appropriate time intervals under a constant sputtering current. Films of $\mathrm{Au}$ or $\mathrm{Ag}$ were deposited on the upper part of the cantilever which vibrated horizontally. Films were also deposited on a silicon wafer under the same sputtering conditions for thickness measurement. The film thickness as a function of deposition time was measured with $\mathrm{Au}$ or $\mathrm{Ag}$ deposited on the silicon wafer by the "multiple-beam interference" method using an optical microscope.

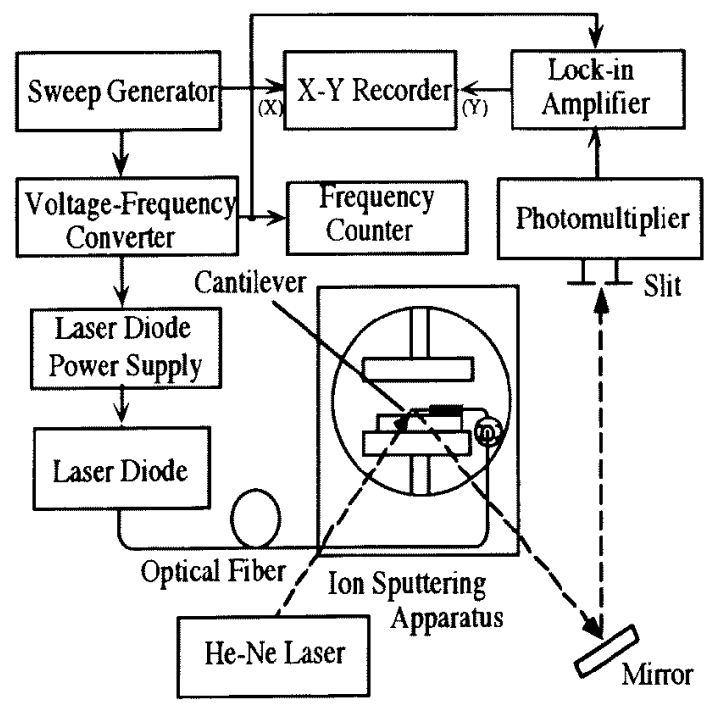

Fig 2 Block diagram of experimental system(dynamic measurement) for measurement of resonance frequencies as a function of deposition time (deposition thickness) .

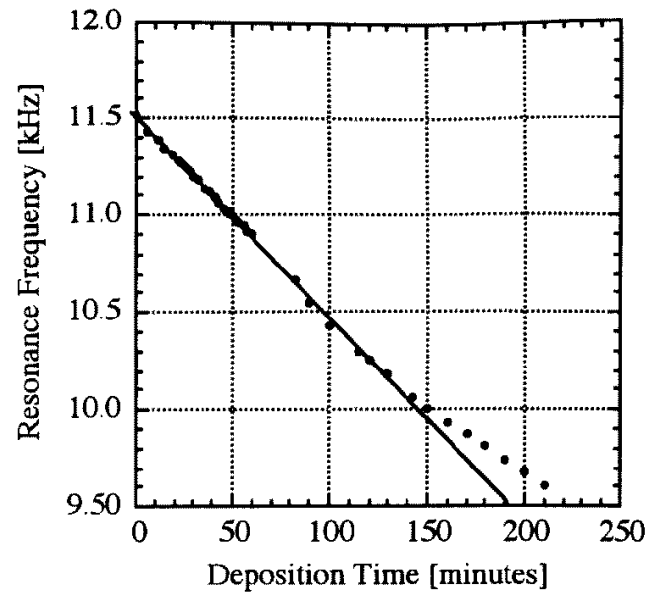

Fig. 3 Resonance frequency as a function of deposition time of $\mathrm{Au}$.

\section{Results and discussion}

Figure 3 shows the resonance frequency as a function of the deposition time of Au when the sputtering current is $10 \mathrm{~mA}$. The resonance frequency linearly decreased with elapse of deposition time to about 150minutes which corresponded to a thickness of $900 \mathrm{~nm}$ and the rate of decrease was about $10.4 \mathrm{~Hz} /$ minute. At least, in this region, film thickness can be measured as a linear function of the resonance frequency. This was mainly caused by changes of flexural rigidity and mass of the cantilever due to the adhesion of $\mathrm{Au}$

Next, the deposition thickness and the deposition time were measured under the above-mentioned sputtering condition. The deposition thickness increased to $360 \mathrm{~nm}$ over a period of 60 minutes in proportion to the deposition time of $\mathrm{Au}$. The adhesion speed of Au was $6 \mathrm{~nm} /$ minute under the condition. From above results, a relation between the resonance frequency and the deposition thickness of $\mathrm{Au}$ was obtained as shown in Fig.4. The resonance frequency almost linearly decreased about $630 \mathrm{~Hz}$ with increase in deposition thickness of $360 \mathrm{~nm}$. The rate of decrease was about $1.75 \mathrm{~Hz} / \mathrm{nm}$. The maximum deviation of the resonance frequency from the approximation line is about $10 \mathrm{~Hz}$. It is mainly caused by measurement errors of resonance frequency and deposition thickness. Since the resonance frequency in a stationary state can be measured with an accuracy of $1 \mathrm{~Hz}$, it can be used for thickness monitoring of Au film with an accuracy better than $1 \mathrm{~nm}$ if accuracies of measurements of resonance frequency and deposition thickness are improved. However, a temperature fluctuation of $1^{\circ} \mathrm{C}$ results in a measurement error of $2.6 \mathrm{~nm}$ of $\mathrm{Au} \mathrm{[4],} \mathrm{and} \mathrm{a} \mathrm{pressure} \mathrm{fluctuation} \mathrm{of} 1 \mathrm{~Pa}$ 


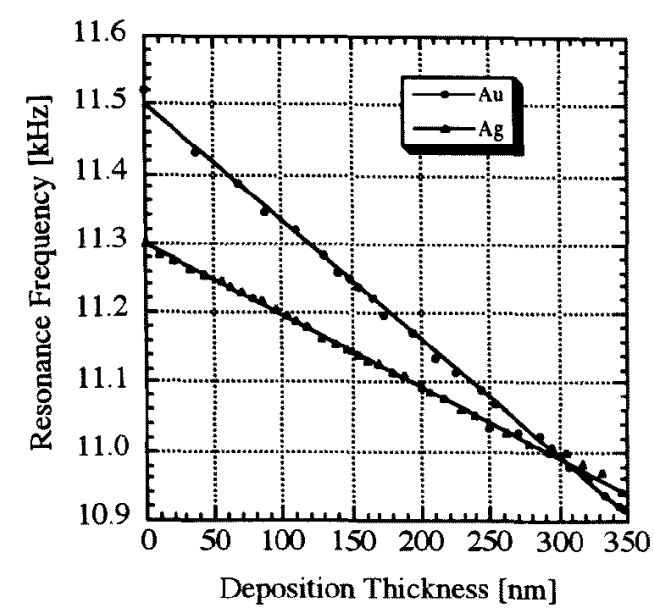

Fig.4 Resonance frequency as a function of deposition thickness of Au and Ag.

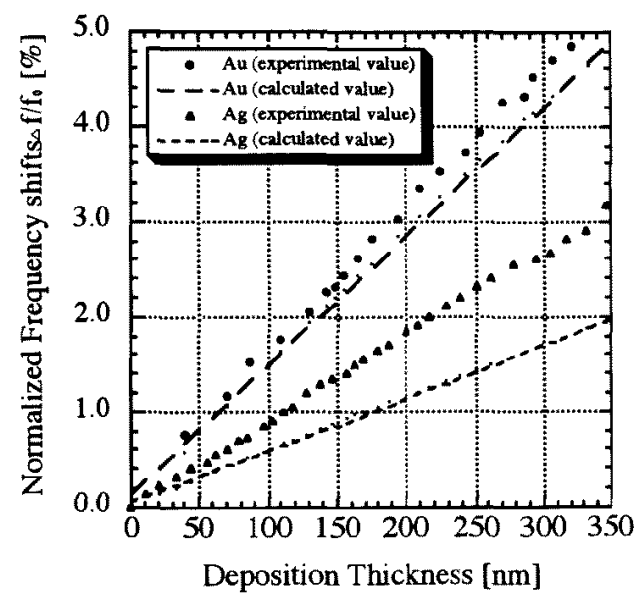

Fig.5 Normalized frequency shifts as a function of deposition thickness of $\mathrm{Au}$ and $\mathrm{Ag}$.

results in a measurement error of $0.16 \mathrm{~nm}$ of $\mathrm{Au}$. The same experiment was performed for $\mathrm{Ag}$. The results are also shown in Fig.4. The resonance frequency decreased almost linearly by about $310 \mathrm{~Hz}$ with an increase in deposition thickness of $300 \mathrm{~nm}$. The rate of decrease was about $1.03 \mathrm{~Hz} / \mathrm{nm}$.

Figure 5 shows normalized frequency shifts $\Delta f / f_{0}$ as a function of the deposition thickness of $\mathrm{Au}$ and $\mathrm{Ag}$. Here, $f_{0}$ is the resonance frequency before deposition, and $\Delta f$ is the frequency shift from $f_{0}$. Applying the theory related to the flexural vibration of a beam, the characteristic frequency $f$ of a cylindrical composite beam is

$$
f=\frac{C^{2}}{2 \pi l^{2}} \sqrt{\sum_{i=1}^{n} \frac{E i J i}{\rho i A i}}
$$

where $l, \rho i$ and $A i$ are the length, densities and cross sectional area of the cantilever, respectively [5][6]. $E i$ and $J i$ are Young's modulus and geometrical moment of inertia, respectively, and $n$ is the number of materials composing a beam. The constant value of $C$ which depends on the vibration mode is 1.875 for first-mode vibration of the cantilever. The cantilever used for $\mathrm{Au}$ deposition has length $=1.70 \mathrm{~mm}$, radius $r=21.0 \mu \mathrm{m}$, and the value of $f_{0}$ calculated using eq.(1) was $11.715 \mathrm{kHz}$. Similarly, the cantilever used for $\mathrm{Ag}$ deposition has $l=1.73 \mathrm{~mm}, r=21.0 \mu \mathrm{m}$, and the calculated value of $f_{0}$ was $11.308 \mathrm{kH}$. In Fig.5, the experimental values are represented by symbols. They monotonically increased with the deposition thickness. The rates of increase were about $0.015 \% / \mathrm{nm}$ in Au deposition and about

$0.009 \% / \mathrm{nm}$ in $\mathrm{Ag}$ deposition. Although the deposited side is perpendicular to the vibration direction of the cantilever, the vibration can be regarded as symmetrical as long as the film thickness is very small in comparison with the radius of the cantilever. The adhesion of $\mathrm{Au}$ and $\mathrm{Ag}$ made both the denominator and the numerator in the root of eq.(1) increase. Since the rate of increase of the denominator was larger than that of the numerator, the resonance frequency decreased with increase in deposition thickness. Dashed lines in Fig. 5 show values calculated using eq.(1). The calculations were performed on the assumption that $\mathrm{Au}$ and $\mathrm{Ag}$ were deposited uniformly around half the circumference of the cantilever with the thickness which was measured using the silicon wafer as shown in Fig.6. Overall tendencies of experimental values and calculated values were similar for both $\mathrm{Au}$ deposition and $\mathrm{Ag}$ deposition. The difference between experimental values and calculated values was caused by the difference of the region and the distribution of the deposition between the actual conditions and those assumed in the model in Fig.6.

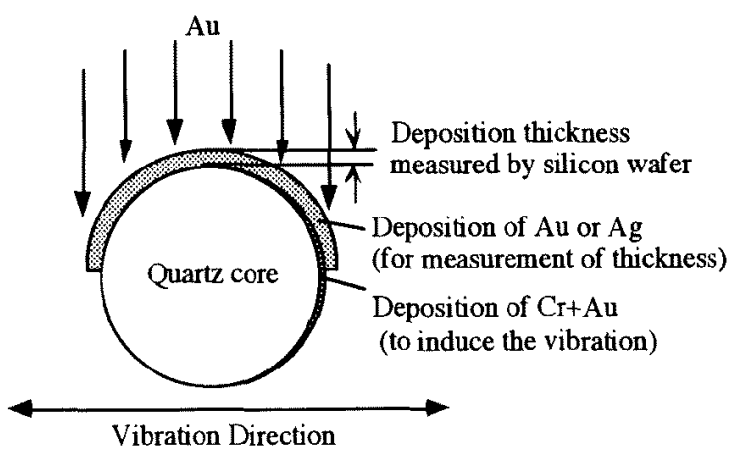

Fig.6 Cross section of a cylindrical composite beam model. Theoretical resonance frequencies were calculated using eq.(1) on this model. 


\section{Conclusion}

The resonance frequencies were measured as a function of the deposition thickness of $\mathrm{Au}$ and $\mathrm{Ag}$ using a quartz core microcantilever fabricated from an optical fiber in an ion sputtering apparatus. Dynamic monitoring of deposition thickness was performed without influence of electrical noise in the ion sputtering apparatus. This cantilever can be utilized for film thickness measurement with an accuracy better than Inm in Au deposition if accuracies of measurements of resonance frequency and deposition thickness are improved. This measurement method is advantageous in terms of time response, sensitivity and noise immunity. The cantilever should be slender in order to obtain a better accuracy.

\section{Acknowledgments}

This work was supported in part by Grants-in-Aid for General Scientific Research and Developmental Scientific Research from the Ministry of Education, Science and Culture. This work was also supported in part by the Endo Foundation.

(Manuscript received Mar. 29, 1996 and revised Aug. 12, 1996)

\section{References}

[1]A.Kinbara: Hakumaku no Kihongijutu (Basic Techniques of Thin Film) (2nd edition, Tokyo Daigaku Syuppankai, Tokyo, 1992) vol. 1,Chap. 6, pp.89 [in Japanese].

[2]S.Inaba, H.Kumazaki and K.Hane, "Photothermal Vibration of Fiber Core for Vibration-Type Sensor," Jpn. J. Appl. Phys., vol.34, pp.2018-2021, 1995.

[3]T.Pangaribuan, K.Yamada, S.Jiang, H.Ohsawa and M.Ohtsu, "Reproducible Fabrication Technique of Nanometric Tip Diameter Fiber Probe for Photon Scanning Tunneling Microscope,"

J. Appl. Phys. vol.31. pp.L1302-L1304, 1992.

[4]H.Kumazaki, S.Inaba and K.Hane,

"Temperature Characteristics of Vibrating Type Sensor

Using Micromachined Optical Fiber-Tip,"

Optical Review., vol.3, pp.135-138, 1996.

[5]A.Watari: Kikai Shindo (Mechanical Vibration) 3rd ed. (Maruzen, Tokyo, 1977) [in Japanese].

[6]T.Miyoshi, M.Shirotori and T.Oda: Zairyo Rikigaku (Strength of Materials)(Jikkyo Shuppan, Tokyo, 1977) [in Japanese].

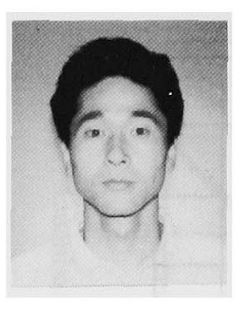

Hironori Kumazaki (Member) received the B.E degree and the M.S degree from Nagaoka university of technology in 1981 and in 1983, respectively. From 1983 to 1994, he worked at Nissin Electric Co., Ltd. Since 1994, he has been working at the Dept. of Electrical Eng. in Gifu National College of Technology, where he began to study in the field of optical microsensors.

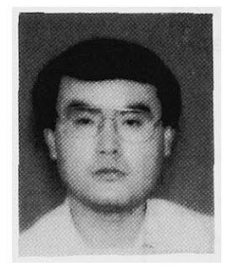

Seiki Inaba (Member) received the M.S degree and the Dr.Eng. Degree from Nagoya university in 1976 and in 1982, respectively. Since 1976, he has been working at the Dept. of Electrical Eng. in Gifu National College of Technology, and is currently engaged in the reserch and developement of optical microactuators. Since 1995, he has been a professor in the Dept. of Electrical Eng. in Gifu National College of Technology. He was awarded the 17 th vacuum technology prize in 1992.

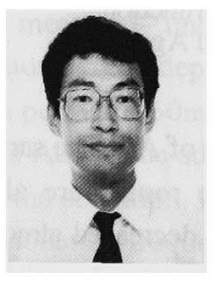

Kazuhiro Hane (Member) received the M.S degree and the Dr.Eng. degree from Nagoya university in 1980 and in 1983, respectively. From 1983 to 1994 , he worked as amember of the Dept. of Electrical Eng. in Nagoya university. From 1985 to 1986 , he was a guest researcher of National Reserch Council of Canada. Since 1994, he has been a professor in the Dept. of Mechatronics and Precision Eng. in Tohoku University, and is currently engaged in the reserch and developement of microsensors and opto-mechanical system. He was awarded the 17 th vacuum technology prize in 1992. 